\title{
Preparation and evaluation of a novel antibacterial glass-ionomer cement
}

\author{
Leah Howard, Yiming Weng, Ruijie Huang, Yuan Zhou, Dong Xie*
}

Department of Biomedical Engineering, Purdue School of Engineering and Technology, Indiana University-Purdue University at Indianapolis, Indianapolis, USA

Email: dxie@iupui.edu

Received 28 October 2013; revised 29 November 2013; accepted 3 December 2013

Copyright (C) 2013 Leah Howard et al. This is an open access article distributed under the Creative Commons Attribution License, which permits unrestricted use, distribution, and reproduction in any medium, provided the original work is properly cited. In accordance of the Creative Commons Attribution License all Copyrights (C) 2013 are reserved for SCIRP and the owner of the intellectual property Leah Howard et al. All Copyright (C 2013 are guarded by law and by SCIRP as a guardian.

\begin{abstract}
A novel antibacterial glass-ionomer cement has been developed. Compressive strength (CS) and $S$. mutans viability were used to evaluate the mechanical strength and antibacterial activity of the formed cement. Compressive yield strength (YS), modulus (M), diametral tensile strength (DTS) and flexural strength (FS) were also determined. All the formulated antibacterial cements showed a significant antibacterial activity, accompanying with an initial CS reduction. The effect of the synthesized antibacterial polymer loading was significant. Increasing loading from $1 \%$ to $20 \%$ significantly decreased the $S$. mutans viability from $3 \%$ to $50 \%$ and also reduced the initial CS (325 MPa) of the formed cements from $19 \%$ to $75 \%$. The cement with $5 \%$ antibacterial polymer loading showed 142 MPa, 6.9 GPa, $224 \mathrm{MPa}$, 52 MPa, and 62 MPa in YS, M, CS, DTS and FS, respectively, as compared to 170, 7.1, 325, 60 and 87 for the experimental cement without antibacterial polymer addition and 141, 6.9, 236, 42 and 53 for Fuji II LC. It was also found that the chlorine-containing antibacterial cement showed better $C S$ values than the bromine-containing cement, with no significant difference in antibacterial activity. The antibacterial cement also showed a similar antibacterial activity to Streptococcus mutans, lactobacillus, Staphylococcus aureus and Staphylococcus epidermidis. The human saliva did not affect the antibacterial activity of the cement. The thirty-day aging study indicates that the cements may have a longlasting antibacterial function.
\end{abstract}

Keywords: Dihalomalealdehydic Acid Derivative;

\footnotetext{
"Corresponding author.
}

Antibacterial Polymer; S. mutans Viability; Glass-Ionomer Cement; CS

\section{INTRODUCTION}

Secondary caries is found to be the main reason for the restoration failure of dental restoratives including resin composites and glass-ionomer cements [1-4]. Secondary caries often occurs at the interface between the restoration and the cavity preparation. One of the main reasons to cause secondary caries is demineralization of tooth structure due to invasion of plaque bacteria (acid-producing bacteria) such as Streptococcus mutans (S. mutans) and lactobacilli in the presence of fermentable carbohydrates [4]. Although numerous efforts have been made on improving antibacterial activities of dental restoratives, most of them have been focused on release or slow-release of various incorporated low molecular weight antibacterial agents such as antibiotics, zinc ions, silver ions, iodine and chlorhexidine [5-9]. Yet release or slow-release can lead or has led to a reduction of mechanical properties of the restoratives over time, shortterm effectiveness, and possible toxicity to surrounding tissues if the dose or release is not properly controlled [5-9]. Materials containing quaternary ammonium salt (QAS) or phosphonium salt groups have been studied extensively as an important antimicrobial material and used for a variety of applications due to their potent antimicrobial activities [10-14]. These materials are found to be capable of reducing the number of bacteria that are resistant to other types of cationic antibacterials [15]. The examples of the QAS-containing materials as antibacterials for dental restoratives include incorporation of a methacryloyloxydodecyl pyridinium bromide as an antibacterial monomer into resin composites [12], use of methacryloxylethyl cetyl ammonium chloride as a com- 
ponent for antibacterial bonding agents [16,17], addition of quaternary ammonium polyethylenimine nanoparticles into composite resins [18-23], and incorporation of polyQAS (PQAS) into glass-ionomer cements (GICs) [24]. All these studies found that the QAS-containing materials did exhibit significant antibacterial activities. However, it has been reported that human saliva can significantly decrease the antibacterial activity of the QAScontaining restoratives, probably due to electrostatic interactions between QAS and proteins in saliva $[25,26]$. Recently furanone derivatives have been found to have strong antitumor [27,28] and antibacterial functions [29]. These compounds all contain a furanone structure (classified as lactone or butenolide) and showed a similarity to natural manoalide, which has an interesting anti-inflammatory activity [30]. The similar compounds were also found to show an inhibitory effect on bacterial quorum-sensing [31], probably due to the structural similarity to autoinducers in bacteria. The exact antibacterial mechanism is still unclear and under investigation. Here we hypothesize that incorporating a newly synthesized furanone derivative to GICs would make a GIC with an antibacterial function, allowing us to explore them in dental applications.

The objective of this study was to synthesize and characterize a new furanone derivative and its containing polyacid, use the polyacid to formulate the light-curable glass-ionomer cements, and study the effect of this derivative on the compressive strength and antibacterial activity of the formed cements. DTS and FS were also determined.

\section{MATERIALS AND METHODS}

\subsection{Materials}

Acrylic acid (AA), glycolic acid (GA), 2,3-dichloromalealdehydic acid (DCA), 2,3-dibromomalealdehydic acid (DBA), dipentaerythritol, 2-bromoisobutyryl bromide (BIBB), 2,2'-azobisisobutyronitrile (AIBN), triethylamine (TEA), CuBr, N,N,N',N',N''-pentamethyldiethylenetriamine (PMDETA), dl-camphoroquinone (CQ), 2-(dimethylamino)ethyl methacrylate (DMAEMA), pyridine, tert-butyl acrylate (t-BA), glycidyl methacrylate (GM), hydrochloric acid ( $\mathrm{HCl}, 37 \%)$, sulfuric acid, pyridine, diethyl ether, dioxane, N,N-dimethylformamide (DMF), toluene, hexane and tetrahydrofuran (THF) were used as received from Sigma-Aldrich Co. (Milwaukee, WI) without further purifications. Light-cured glassionomer cement Fuji II LC and Fuji II LC glass powders (Batch \# 0704101) were used as received from GC Corp (Japan).

\subsection{Synthesis and Characterization}

2.2.1. Synthesis of the DCA Methacrylate Derivative To a solution containing DCA $(0.5 \mathrm{~mol})$, toluene and sulfuric acid ( $1 \%$ by mole), glycolic acid $(0.55 \mathrm{~mol})$ in toluene was added. The reaction was run at $90-100^{\circ} \mathrm{C}$ for $3-4 \mathrm{~h}$ until no more water came out. Then toluene was removed using a rotary evaporator. The formed DCAGA was purified by washing with sodium bicarbonate and distilled water. After freeze-drying, DCAGA $(0.5 \mathrm{~mol})$ was mixed with $\mathrm{GM}(0.52 \mathrm{~mol})$ and pyridine ( $3 \%$, by weight) in DMF to form DCAGAGM. The mixture was reacted at $50^{\circ} \mathrm{C}$ for $8 \mathrm{~h} \mathrm{[32],} \mathrm{followed} \mathrm{by}$ washing with hexane and diethyl ether and drying in a vacuum oven prior to use. DBAGAGM was synthesized similarly. The synthesis scheme is shown in Figure 1(a).

\subsubsection{Synthesis of the Poly(Acrylic Acid-Co-DCAGAGM)}

The linear poly(acrylic acid-co-DCAGAGM) copolymer or abbreviated as CAP (chlorine-containing antibacterial polymer) was prepared following our published procedures [33]. Briefly, to a flask containing a solution of AA $(0.1 \mathrm{~mol})$ and DCAGAGM $(0.1 \mathrm{~mol})$ in THF, AIBN $(1 \%$ by mole) in THF was added. After the reaction was run under $\mathrm{N}_{2}$ purging at $60^{\circ} \mathrm{C}$ for $18 \mathrm{~h}$, the polymer was precipitated with diethyl ether, followed by drying in a vacuum oven. The synthesis scheme is shown in Figure 1(b).

\subsubsection{Synthesis of the GM-Tethered Star-Shape Poly(Acrylic Acid)}

The GM-tethered 6-arm star-shaped poly(acrylic acid) (PAA) was synthesized similarly as described in our previous publication [34]. Briefly, dipentaerythritol $(0.06$ $\mathrm{mol})$ in $200 \mathrm{ml}$ THF was used to react with BIBB $(0.48$ mol) in the presence of TEA $(0.35 \mathrm{~mol})$ to form the 6-arm initiator. t-BA $(0.078 \mathrm{~mol})$ in $10 \mathrm{ml}$ dioxane was then polymerized with the 6 -arm initiator ( $1 \%$ by mole) at $120^{\circ} \mathrm{C}$ in the presence of $\mathrm{CuBr}(3 \%)$-PMDETA (3\%) catalyst complex via atom-transfer radical polymerization. The resultant 6-arm poly(t-BA) was hydrolyzed with $\mathrm{HCl}$ and dialyzed against distilled water. The purified star-shape PAA was obtained via freeze-drying, followed by tethering with GM ( $50 \%$ by mole) in DMF in the presence of pyridine ( $1 \%$ by weight) [34]. The GMtethered star-shaped PAA was recovered by precipitation from diethyl ether, followed by drying in a vacuum oven at room temperature. The synthesis scheme is shown in Figure 1(c).

\subsubsection{Characterization}

The chemical structures of the synthesized furanone derivatives were characterized by Fourier transform-infrared (FT-IR) spectroscopy and nuclear magnetic resonance (NMR) spectroscopy. The proton NMR ( ${ }^{1}$ HNMR) spectra were obtained on a $500 \mathrm{MHz}$ Bruker NMR spectrometer (Bruker Avance II, Bruker BioSpin Corporation, 
(a) Synthesis of functional anitibacterial monomer<smiles>[X]C1=C(OCC(=O)OCC(C)C)C([X])=C([Y])[C@H](OCC(=O)OCC(C)COC(=O)C(=C)C)OC1=O</smiles>

(b) Synthesis of functional antibacterial polymer<smiles>[X]C1=C([X])C(OCC(=O)OCC(O)COC(=O)C(C)(C)CC(C)(C)C(=O)O)OC1OCC(=O)OCC(O)COC(=O)C(=C)C</smiles>

(c) Synthesids of in situ photo-curable star-shaped poly(acrylic acid)

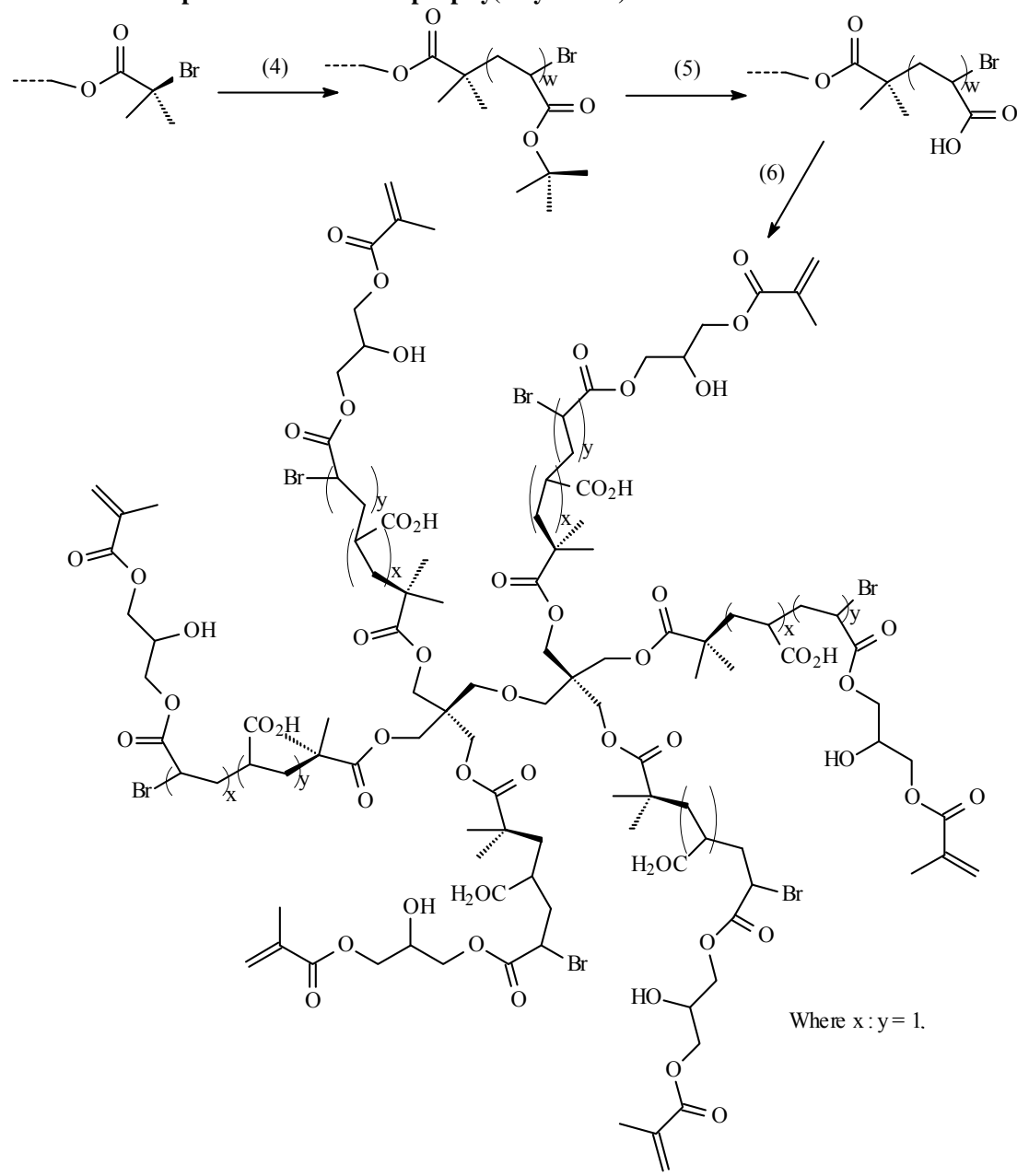

(1) $\mathrm{GA} / \mathrm{H}_{2} \mathrm{SO}_{4}$; (2) GM/pyridine; (3) AA/AIBN; (4) t-BA/CuBr/PMDETA;

(5) Hydrolysis via $\mathrm{HCl}$ (37\%); (6) $\mathrm{GM} /$ pyridine

Figure 1. Schematic diagrams for synthesis of antibacterial monomer, antibacterial polymer and in situ polymerizable 6-arm star-shaped polymer: (a) DCAGAGM synthesis; (b) poly(AA-co-DCAGAGM) synthesis; (c) Synthesis of the 6-arm star-shaped poly(AA) with pendent methacrylates. 
Billerica, MA) using deuterated dimethyl sulfoxide and chloroform as solvents and FT-IR spectra were obtained on a FT-IR spectrometer (Mattson Research Series FT/IR 1000, Madison, WI).

\subsection{Evaluation}

\subsubsection{Cement Sample Preparation for Strength and Antibacterial Tests}

The experimental cements were formulated with a twocomponent system (liquid and powder) [34]. The liquid was formulated with the light-curable star-shaped PAA, water, $0.9 \%$ CQ (photo-initiator, by weight) and $1.8 \%$ DMAEMA (activator). The polymer/water $(\mathrm{P} / \mathrm{W})$ ratio $=$ 70:30 (by weight). Fuji II LC glass powder was either used alone or mixed with the synthesized poly(AA-coDCAGAGM) or CAP to formulate the cements, where the polymer loading ratio $=1,3,5,7,10$, or $20 \%$ (by weight) of the glass and the powder/liquid $(\mathrm{P} / \mathrm{L})$ ratio $=$ 2.7 (by weight).

Specimens were fabricated at room temperature according to the published protocol [34]. Briefly, the cylindrical specimens were prepared in glass tubing with dimensions of $4 \mathrm{~mm}$ in diameter by $8 \mathrm{~mm}$ in length for compressive strength (CS), $4 \mathrm{~mm}$ in diameter by $2 \mathrm{~mm}$ in length for diametral tensile strength (DTS), and $4 \mathrm{~mm}$ in diameter by $2 \mathrm{~mm}$ in depth for antibacterial tests. The rectangular specimens were prepared in a split Teflon mold with dimensions of $3 \mathrm{~mm}$ in width by $3 \mathrm{~mm}$ in thickness by $25 \mathrm{~mm}$ in length for flexural strength (FS) test. All the specimens were exposed to blue light (LED, $30 \mathrm{~W}$, EXAKT 520 Blue Light Polymerization Unit, EXAKT Technologies, Inc., Oklahoma City, OK) for 2 min, followed by conditioning in $100 \%$ humidity at room temperature for $15 \mathrm{~min}$, removing from the mold and conditioning in distilled water at $37^{\circ} \mathrm{C}$ for $24 \mathrm{~h}$ prior to testing, unless specified.

\subsubsection{Strength Measurements}

CS, DTS and FS tests were performed on a screw-driven mechanical tester (QTest QT/10, MTS Systems Corp., Eden Prairie, MN), with a crosshead speed of $1 \mathrm{~mm} / \mathrm{min}$. The FS test was performed in three-point bending with a span of $20 \mathrm{~mm}$ between supports. Six specimens were tested to obtain a mean value for each material or formulation in each test. CS was calculated using an equation of $\mathrm{CS}=\mathrm{P} / \pi \mathrm{r}^{2}$, where $\mathrm{P}=$ the load at fracture and $\mathrm{r}=$ the radius of the cylinder. DTS was determined from the relationship DTS $=2 \mathrm{P} / \pi \mathrm{dt}$, where $\mathrm{P}=$ the load at fracture, $\mathrm{d}=$ the diameter of the cylinder, and $\mathrm{t}=$ the thickness of the cylinder. FS was obtained using the expression FS = $3 \mathrm{Pl} / 2 \mathrm{bd}^{2}$, where $\mathrm{P}=$ the load at fracture, $1=$ the distance between the two supports, $b=$ the breadth of the specimen, and $\mathrm{d}=$ the depth of the specimen. Compressive yield strength (YS) and modulus (M) were obtained from the stress-strain curves of CS tests.

\subsubsection{MIC Test for the Synthesized Antibacterial Monomers}

The minimal inhibitory concentration (MIC) of the synthesized antibacterial monomers was determined following the published protocol with a slight modification [24]. Briefly, colonies of S. mutans (UA159) were suspended in $5 \mathrm{ml}$ of Tryptic soy Broth (TSB) prior to MIC testing. Two-fold serial dilutions of the synthesized monomer were prepared in TSB, followed by placing in 96-well flat-bottom microtiter plates with a volume of $250 \mu \mathrm{l}$ per well. The final concentration of the monomer ranged from 1.563 to $2 \times 10^{4} \mu \mathrm{g} / \mathrm{ml}$. The microtiter plate was then inoculated with $S$. mutans suspension (cell concentration $=5 \times 10^{5} \mathrm{CFU} / \mathrm{ml}$ ) and incubated at $37^{\circ} \mathrm{C}$ for $48 \mathrm{~h}$ prior to MIC testing. The absorbance was measured at $595 \mathrm{~nm}$ via a microplate reader (SpectraMax 190, Molecular Devices, CA) to assess the cell growth. Chloehexidine (CHX) and dimethylsulfoxide were used as positive and negative controls, respectively [24]. The concentration of CHX was used in the same range as shown for the monomers. The final concentration of dimethylsulfoxide was $2 \%(\mathrm{v} / \mathrm{v})$. Triple replica was used to obtain a mean value for each material.

\subsubsection{Antibacterial Test}

The antibacterial test was conducted following the published procedures [24]. S. mutans was mainly used to evaluate the antibacterial activity of the studied cements throughout the study. Other bacteria including lactobacillus, Staphylococcus aureus (S. aureus) and Staphylococcus epidermidis (S. epidermidis) were also used to evaluate a broad antibacterial activity of the studied cements. Briefly, colonies of S. mutans (UA159) were suspended in $5 \mathrm{ml}$ of Tryptic soy Broth (TSB), supplemented with $1 \%$ sucrose, to make a suspension with $10^{8}$ $\mathrm{CFU} / \mathrm{ml}$ of $S$. mutans, after $24 \mathrm{~h}$ incubation. Each cement specimen was dipped in $70 \%$ ethanol for $10 \mathrm{sec}$, followed by drying in the air for another $10-20 \mathrm{sec}$ and placing in a vial containing $5 \mathrm{ml}$ TSB supplemented with $1 \%$ sucrose. To the specimen-containing TSB, $100 \mu$ of the above incubated $S$. mutans suspension was added. After incubating at $37^{\circ} \mathrm{C}$ for $48 \mathrm{~h}$ under anaerobic condition with $5 \% \mathrm{CO}_{2}$, the specimen-containing suspension was sonicated for $20 \mathrm{sec}$ to remove the adhered bacteria off the specimen. $1 \mathrm{ml}$ of the suspension was then used to mix with $3 \mu \mathrm{l}$ of a two-color dye, which was formed by thoroughly mixing equal volumes of the red and the green dyes (LIVE/DEAD BacLight bacterial viability kit L7007, Molecular Probes, Inc., Eugene, OR, USA) in a microfuge tube for $1 \mathrm{~min}$. The formed mixture was vortexed for $10 \mathrm{sec}$, sonicated for $10 \mathrm{sec}$, vortexed for another $10 \mathrm{sec}$, and kept in dark for about $15 \mathrm{~min}$, prior to 
analysis. Then $20 \mu \mathrm{l}$ of the stained bacterial suspension was analyzed using a fluorescent microscope (Nikon Microphot-FXA, Melville, NY, USA). Triple replica was used to obtain a mean value for each material.

\subsubsection{Saliva Effect Test}

Human saliva, obtained from a healthy volunteer, was centrifuged for $15 \mathrm{~min}$ at $12,000 \mathrm{~g}$ to remove debris [25]. After the supernatant was filtered with a $0.45 \mu \mathrm{m}$ sterile filter, the filtrate was stored in a $-20^{\circ} \mathrm{C}$ freezer prior to use. The sterilized cement specimen (see Section 2.3.4) was incubated in a small tube containing $1 \mathrm{ml}$ of saliva at $37^{\circ} \mathrm{C}$ for $2 \mathrm{~h}$, followed by placing in $5 \mathrm{ml}$ TSB supplemented with $1 \%$ sucrose. The rest of the procedures for antibacterial test are the same as described in Section 2.3.4.

\subsubsection{Aging of the Specimens}

The specimens for both $\mathrm{CS}$ and antibacterial activity aging tests were conditioned in distilled water at $37^{\circ} \mathrm{C}$ for 1 day, 3 days, 7 days and 30 days, followed by direct testing for CS (see Section 2.3.2 for details) and incubating with $S$. mutans for $48 \mathrm{~h}$ for antibacterial testing (see Section 2.3.4 for details).

\subsubsection{Statistical Analysis}

One-way analysis of variance (ANOVA) with the post hoc Tukey-Kramer multiple-range test was used to determine significant differences of mechanical strength and antibacterial tests among the materials or formulations in each group. A level of $\alpha=0.05$ was used for statistical significance.

\section{RESULTS}

\subsection{Characterization}

Figure 2 shows the FT-IR spectra of GA, DCA, DCAGA, GM and DCAGAGM. The disappearance of the peak $\left(\mathrm{cm}^{-1}\right)$ at 3362 for pseudo hydroxyl group on pseudo ester and appearance of the two new peaks at 1810 and 1768 for the carbonyl groups from pseudo ester and GA ester as well as a broad $\mathrm{COOH}$ peak at 36502500 confirmed the formation of DCAGA. The disappearance of the broad carboxylic acid peak at 3650-2500 and appearance of $3480(\mathrm{OH}), 3001-2930\left(\mathrm{CH}_{3}\right), 1786$, 1742 and $1720(\mathrm{C}=\mathrm{O}$ from pseudo ester, $\mathrm{GA}$ ester and methacrylate), and 1638 and $1620(\mathrm{C}=\mathrm{C}$ on methacrylate and pseudo ester) confirmed the formation of DCAGAGM. Table 1 shows the ${ }^{1}$ HNMR chemical shifts (ppm) for GA, DCA, DCAGA, GM and DCAGAGM. All the new chemical shifts shown in Table 1 for DCAGAGM confirmed the formation of DCAGAGM.

\subsection{Evaluation}

Figure 3 shows the effect of the chlorine-containing an- tibacterial polymer or CAP content on CS (a) and S. mutans viability (b) of the cements. Both mean CS and $S$. mutans viability values decreased with increasing CAP content, where there were no statistically significant differences between $1 \%$ and $3 \%$ for CS and among Fuji II LC, $0 \%$ and $1 \%$, between $1 \%$ and $3 \%$, and between $7 \%$ and $10 \%$ for the $S$. mutans viability ( $p>0.05$ ). The CAP addition significantly decreased both $\mathrm{CS}$ and $S$. mutans viability, with a reduction of $19 \%$ to $75 \%$ for CS and $3 \%$ to $50 \%$ for the $S$. mutans viability.

Table 2 shows the MIC of DCA, DBA, DCAGAGM, DBAGAGM and CHX to $S$. mutans, lactobacillus, $S$. aureus and $S$. epidermidis. The MIC values ranged from 9.36 to $74.9 \mu \mathrm{g} / \mathrm{ml}$ for DCA and DBA, 4.68 to 150 for DCAGAGM and DBAGAGM, and 1.563 to 6.25 for CHX.

Table 3 shows the effect of both CAP and bromidecontaining antibacterial polymer (BAP) on CS and $S$. mutans viability of EXPGIC. Like those CAP in Figure 3 , increasing the loading of BAP decreased the CS values of the cements and $S$. mutans viability. By comparison, it is clear that at the same loading the BAP cements showed statistically lower CS values than the CAP cements, although both were not statistically significant different from each other in antibacterial activity.

Figure 4 shows the effect of the CAP cement aging on CS and $S$. mutans viability. After 30-day aging in water, the cement with 7\% CAP addition showed a significant CS increase $(26 \%)$. However, no statistically significant changes were found in the $S$. mutans viability for the cement.

Figure 5 shows the effect of the CAP content on the viability of four bacteria including $S$. mutans, lactobacillus, $S$. aureus and $S$. epidermidis. Increasing CAP decreased the viability of all the bacteria, where there were no statistically significant differences in viability between $7 \%$ and $10 \%$ for $S$. mutans, between $5 \%$ and $7 \%$ for lactobacillus and between $10 \%$ and $20 \%$ for S. epidermidis $(\mathrm{p}>0.05)$. With $20 \%$ of CAP addition, the viability of all four bacteria decreased to $47 \%$.

Figure 6 shows the effect of human saliva on the $S$. mutans viability after culturing with the antibacterial cements. No statistically significant differences in the $S$. mutans viability were found between the cements with and without human saliva treatment.

Table 4 shows the property comparison among the cements with $0 \%, 5 \%$ and $7 \%$ of CAP addition and Fuji II LC. As compared to the cement with $0 \%$ CAP, the cements with $5 \%$ and $7 \%$ CAP showed a decrease in all the measured strengths. The decreases of $16 \%$ to $27 \%$, $3 \%$ to $11 \%, 31 \%$ to $41 \%, 13 \%$ to $20 \%$ and $29 \%$ to $32 \%$ were observed, respectively, in yield strength (YS), compressive modulus (M), CS, diametral tensile strength (DTS) and flexural strength (FS), among which CS and 


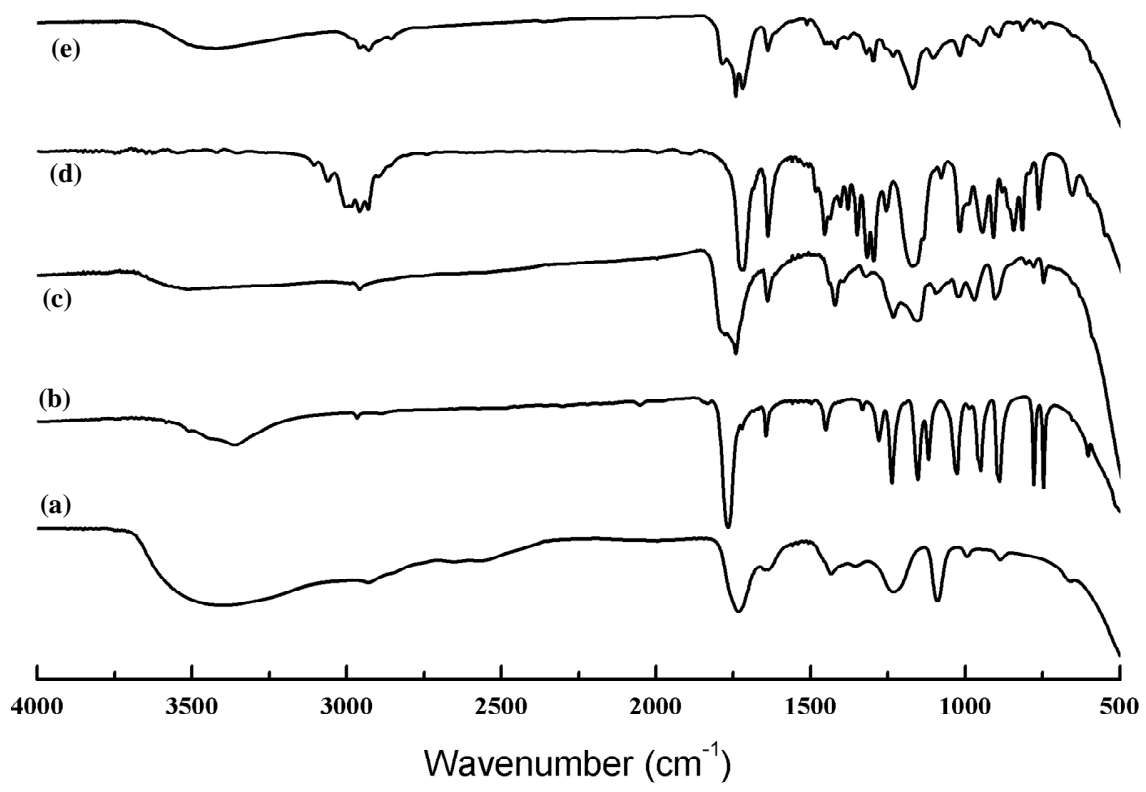

Figure 2. FT-IR spectra for GA, DCA, DCAGA, GM and DCAGAGM: (a) GA; (b) DCA; (c) DCAGA; (d) GM and (e) DCAGAGM.

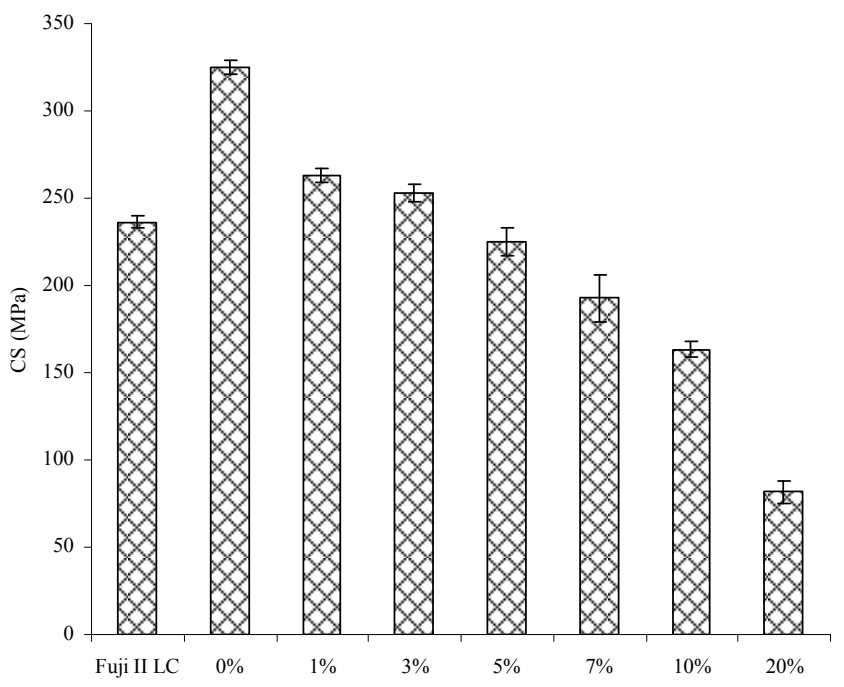

(a)

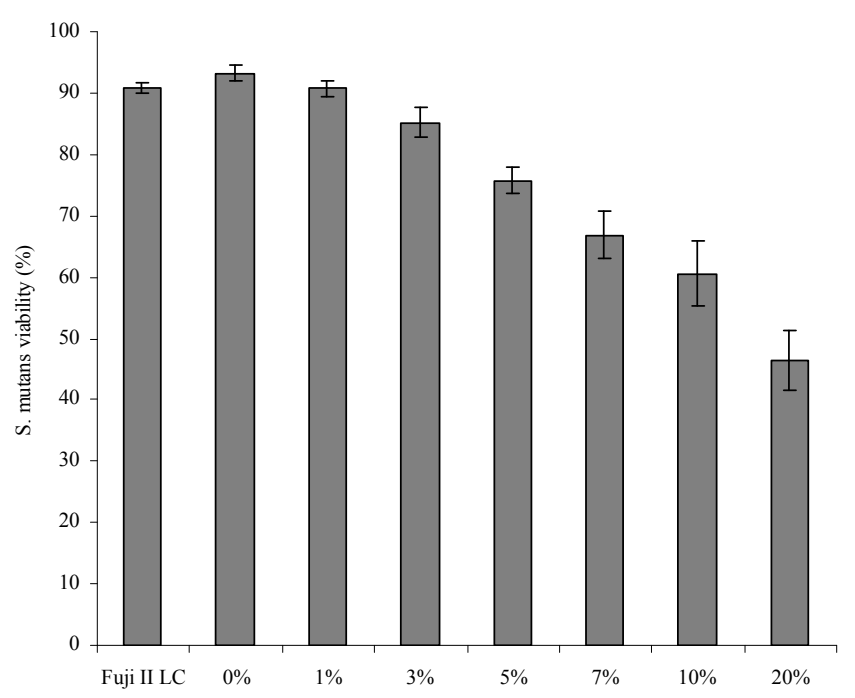

(b)

Figure 3. Effect of the CAP content on CS and S. mutans viability of the experimental cements: (a) Effect on CS and (b) Effect on the $S$. mutans viability. MW of the 6-arm poly(acrylic acid) $=17,530$ Daltons; Filler $=$ Fuji II LC or Fuji II LC + CAP; Grafting ratio $=50 \% ; \mathrm{P} / \mathrm{L}$ ratio $=2.7 ; \mathrm{P} / \mathrm{W}$ ratio $=70: 30$. Fuji II LC was used as control. Specimens were conditioned in distilled water at $37^{\circ} \mathrm{C}$ for $24 \mathrm{~h}$, followed by direct testing for CS or/and incubating with $S$. mutans for $48 \mathrm{~h}$ for antibacterial testing.

Table 1. The characteristic chemical shifts from the ${ }^{1} \mathrm{HNMR}$ spectra.

\begin{tabular}{cc}
\hline Material & The characteristic chemical shifts $(\mathrm{ppm})$ \\
\hline GA & $11.55(-\mathrm{COOH}), 4.57\left(-\mathrm{CH}_{2}-\right)$ and $3.90(-\mathrm{OH})$ \\
DCA & $6.25(-\mathrm{CH})$ and $3.45(-\mathrm{OH})$ \\
DCAGA & $11.55(-\mathrm{COOH}), 6.25(-\mathrm{CH})$ and $4.90\left(-\mathrm{CH}_{2}-\right)$ \\
GM & 6.10 and $5.70\left(\mathrm{H}_{2} \mathrm{C}=\mathrm{C}-\right), 5.45(-\mathrm{CH}), 3.2-3.3\left(-\mathrm{CH}_{2}-\right), 2.65-2.8\left(-\mathrm{CH}_{2}-\right)$ and $1.90(-\mathrm{C}=\mathrm{CH}-)$ \\
DCAGAGM & $6.20(-\mathrm{CH}), 6.10$ and $5.70\left(\mathrm{H}_{2} \mathrm{C}=\mathrm{C}-\right), 4.90\left(-\mathrm{CH}_{2}-\right.$ on $\left.\mathrm{GM}\right), 4.15\left(-\mathrm{CH}_{2}-\right.$ on $\left.\mathrm{GM}\right)$, \\
& $3.70(-\mathrm{CH}-$ on $\mathrm{GM}), 3.50\left(-\mathrm{CH}_{2}-\right.$ on $\left.\mathrm{GA}\right), 3.25(-\mathrm{OH})$ and $1.90(-\mathrm{C}=\mathrm{CH}-)$ \\
\hline
\end{tabular}


Table 2. MIC values of the materials used in the study.

\begin{tabular}{ccccc}
\hline Compounds $^{1}$ & S. mutans & lactobacillus & S. aureus & S. epidermidis \\
\hline DCA & $9.36^{2}$ & 18.7 & 18.7 & 37.7 \\
DBA & 37.4 & 74.9 & 9.3 & 37.4 \\
DCAGAGM & 18.7 & 18.7 & 74.9 & 4.68 \\
DBAGAGM & 74.9 & 150 & 3.12 & 74.9 \\
Chloehexidine & 1.56 & 6.25 & 3.12 \\
\hline
\end{tabular}

${ }^{1}$ DCA, DBA, DCAGAGM and DBAGAGM are the abbreviations of antibacterial compounds, which can be found under Materials and Methods; ${ }^{2}$ MIC values $(\mu \mathrm{g} / \mathrm{ml})$ were measured as described in the text.

Table 3. Effect of CAP and BAP on CS and S. mutans viability of EXPGIC ${ }^{1}$.

\begin{tabular}{ccccc}
\hline Polymer $^{2}[\%]$ & CS & & \multicolumn{2}{c}{ S. mutans viability [\%] } \\
\hline & CAP & BAP & CAP & BAP \\
\hline 1 & $263.1(4.2)^{\mathrm{a}, 3}$ & $231.2(2.3)$ & $90.7(1.2)^{\mathrm{b}, \mathrm{A}}$ & $89.2(1.9)^{\mathrm{d}, \mathrm{A}}$ \\
5 & $252.8(5.1)^{\mathrm{a}}$ & $201.4(4.2)$ & $85.2(2.4)^{\mathrm{b}, \mathrm{B}}$ & $84.2(2.5)^{\mathrm{d}, \mathrm{B}}$ \\
7 & $224.7(7.8)$ & $179.1(0.8)$ & $75.7(2.2)^{\mathrm{C}}$ & $72.3(3.4)^{\mathrm{C}}$ \\
10 & $192.5(13)$ & $145.2(2.1)$ & $66.9(4.0)^{\mathrm{c}, \mathrm{D}}$ & $64.2(1.7)^{\mathrm{e}, \mathrm{D}}$ \\
\hline
\end{tabular}

${ }^{1}$ The formulations were the same as those described in Figure 3, except that CAP contains chlorine but BAP contains bromine; ${ }^{2}$ Polymer $=$ antibacterial polymer $\left(\%\right.$, by weight); ${ }^{3}$ Entries are mean values with standard deviations in parentheses and the mean values with the same superscript letter were not significantly different $(\mathrm{p}>0.05)$. Specimens were conditioned in distilled water at $37^{\circ} \mathrm{C}$ for $24 \mathrm{~h}$, followed by direct testing for CS or/and incubating with $S$. mutans for $48 \mathrm{~h}$ for antibacterial testing.

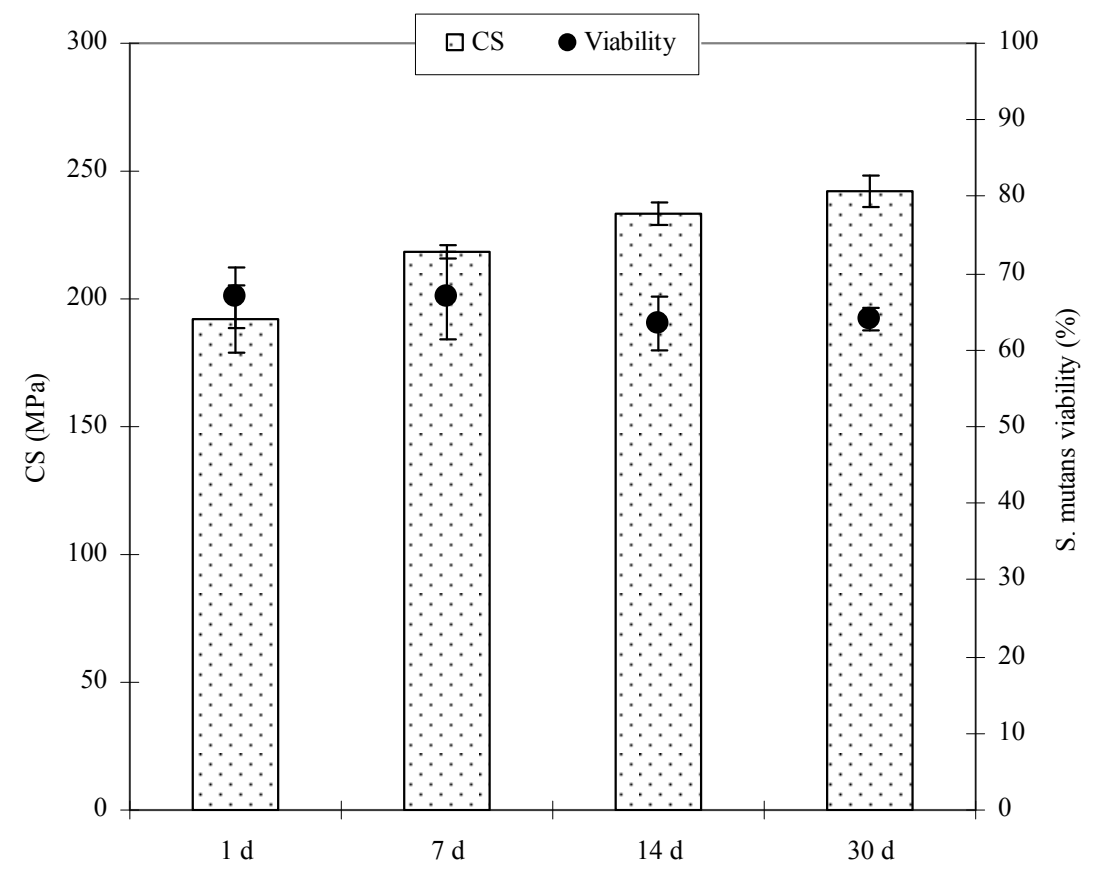

Figure 4. Effect of aging on CS and S. mutans vialibility of the experimental cements: The formulations were the same as those described in Figure 3, except for the CAP content $=7 \%$. Specimens were conditioned in distilled water at $37^{\circ} \mathrm{C}$ for $1,7,14$ and 30 days, followed by direct testing for CS or/and incubating with S. mutans for $48 \mathrm{~h}$ for antibacterial testing. 


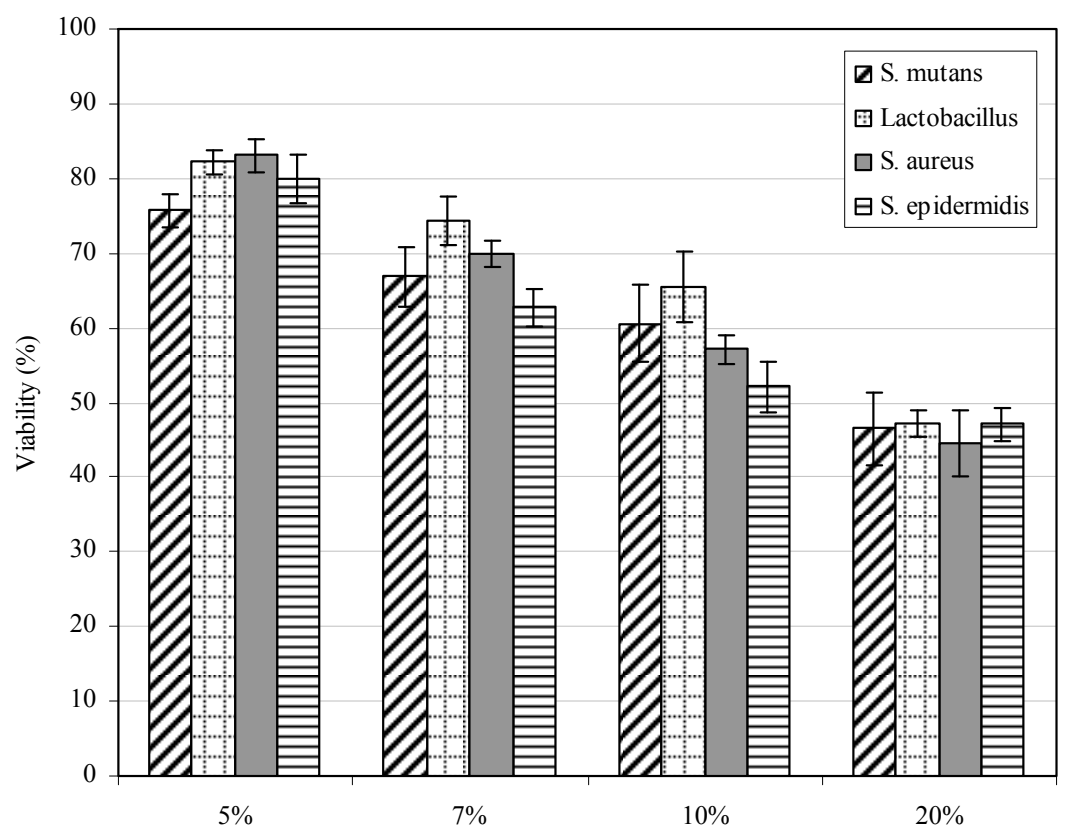

Figure 5. Effect of the CAP content on the viability of different bacteria after culturing with the experimental cements: The formulations were the same as those described in Figure 3. Specimens were conditioned in distilled water at $37^{\circ} \mathrm{C}$ for 24 $\mathrm{h}$, followed by direct testing for CS or/and incubating with $S$. mutans for $48 \mathrm{~h}$ for antibacterial testing.

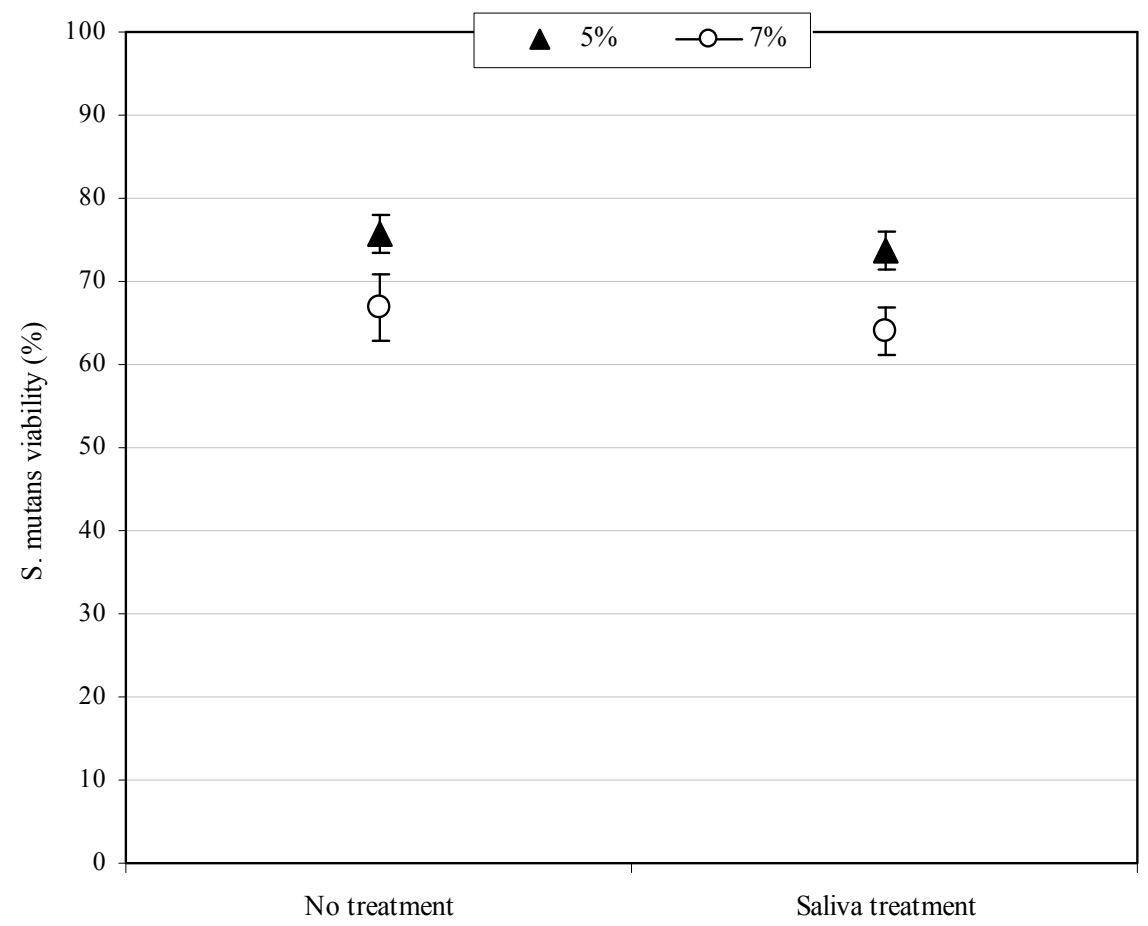

Figure 6. Effect of human saliva on the $S$. mutans viability after culturing with the cements: The formulations were the same as those described in Figure 3. Specimens were incubated in human saliva at $37^{\circ} \mathrm{C}$ for $2 \mathrm{~h}$, followed by incubating with $S$. mutans for $48 \mathrm{~h}$ for antibacterial testing.

FS showed more reduction. A significant decrease with a $19 \%-28 \%$ reduction was observed in the S. mutans vi- ability. Commercial GIC Fuji II LC showed the similar YS, M and CS values to but lower DTS and FS values 
Table 4. Comparison of properties of the experimental cements with and without $\mathrm{CAP}^{1}$.

\begin{tabular}{ccccccc}
\hline Polymer $(\%)^{2}$ & YS $^{3}[\mathrm{MPa}]$ & $\mathrm{M}^{4}[\mathrm{GPa}]$ & $\mathrm{CS}[\mathrm{MPa}]$ & $\mathrm{DTS}^{5}[\mathrm{MPa}]$ & $\mathrm{FS}^{6}[\mathrm{MPa}]$ & Viability $(\%)$ \\
\hline 0 & $170.1(5.6)^{8}$ & $7.12(0.12)$ & $325.3(4.2)$ & $60.1(0.9)$ & $87.2(2.2)$ & $93.2(1.3)^{\mathrm{g}}$ \\
5 & $142.3(6.9)^{\mathrm{a}}$ & $6.86(0.17)^{\mathrm{b}}$ & $224.7(7.9)^{\mathrm{c}}$ & $52.2(2.3)^{\mathrm{d}}$ & $62.1(3.3)^{\mathrm{e}}$ & $75.7(2.2)$ \\
7 & $124.6(5.9)$ & $6.31(0.05)$ & $192.5(13)$ & $48.3(1.1)^{\mathrm{d}}$ & $58.9(4.6)^{\mathrm{e}, \mathrm{f}}$ & $66.9(4.0)$ \\
Fuji II LC & $141.2(1.9)^{\mathrm{a}}$ & $6.89(0.38)^{\mathrm{b}}$ & $236.2(3.4)^{\mathrm{c}}$ & $42.8(0.9)$ & $53.3(2.1)^{\mathrm{f}}$ & $90.9(0.9)^{\mathrm{g}}$ \\
\hline
\end{tabular}

${ }^{1}$ The formulations were the same as those described in Figure $3 ;{ }^{2}$ Polymer $=\mathrm{CAP} ;{ }^{3} \mathrm{YS}=\mathrm{CS}$ at yield; ${ }^{4} \mathrm{M}=$ compressive modulus; ${ }^{5} \mathrm{DTS}=$ diametral tensile strength; ${ }^{6} \mathrm{FS}=$ flexural strength; ${ }^{7} \mathrm{Fuji}$ II LC $=$ commercial GIC; ${ }^{8}$ Entries are mean values with standard deviations in parentheses and the mean values with the same superscript letter were not significantly different $(\mathrm{p}>0.05)$. Specimens were conditioned in distilled water at $37^{\circ} \mathrm{C}$ for $24 \mathrm{~h}$, followed by direct testing for all the strengths and incubating with $S$. mutans for $48 \mathrm{~h}$ for antibacterial testing.

than the experimental cement with 5\% CAP. Fuji II LC also showed the similar S. mutans viability to the cement with $0 \%$ CAP.

\section{DISCUSSION}

Figure 3 shows the effect of the CAP content on CS and $S$. mutans viability of the cements. It is apparent that with CAP addition the cement showed a decrease in CS and S. mutans viability. The cements lost $19 \%$ to $75 \%$ of its original CS value (325 MPa) with $1 \%$ to $20 \%$ CAP addition, among which the cements with $5 \%$ and $7 \%$ CAP showed a $30 \%$ to $40 \%$ loss but the values were still close to $200 \mathrm{MPa}$. The loss of CS can be attributed to the incorporated CAP because hydrophobic CAP did not contribute any strength enhancement to the cements. Regarding the $S$. mutans viability, CAP significantly increased the antibacterial activity of the cement. With $1 \%$ to $20 \%$ CAP addition, the $S$. mutans viability was reduced from $3 \%$ to $50 \%$, among which the cements with $5 \%$ and $7 \%$ CAP showed a $19 \%$ to $28 \%$ reduction. Considering the feasibility of GICs applied in dental clinics, the CS value below 200 MPa may not be well acceptable because the CS values of most commercially available light-cured GICs are in the range of 180 to $240 \mathrm{MPa}$ [5,35]. Therefore, the cements with $5 \%$ and $7 \%$ CAP addition were chosen to evaluate other properties.

Due to the smaller size of chlorine, we hypothesized that CAP might favor the mechanical strength as compared to BAP, although we did not know if their antibacterial activity would be different. The result in Table 3 shows that the CAP cements were statistically significantly higher in CS than the BAP cements, indicating that our hypothesis was correct, i.e., smaller chlorine favors CS. However, no significant differences in antibacterial activity were found between CAP and BAP cements (see Table 3), despite the fact that DCA and DCAGAGM were higher in inhibition of all the four bacteria strains than DBA and DBAGAGM based on MIC test (see Table 2). The result suggests that the CAP cement might be a better choice for cement formulation than the cement on behalf on CS and antibacterial tests.
It is well known that GICs increase their strengths with time due to constant salt-bridge formations [36]. To confirm if the CAP-modified GIC still follows the pattern that most GICs exhibit, we examined both CS and antibacterial activity of the cements after aging in water for 1 day, 7 days, 14 days and 30 days. The result in Figure 4 shows that the cements with 7\% CAP showed 26\% increase in CS after 30-day aging in water and no changes in the $S$. mutans viability were found. The reason can be attributed to the fact that CAP is a copolymer of acrylic acid and DCAGAGM. It is known that the carboxylic acid group plays a key role in GIC setting and salt-bridge formation. CAP not only provided antibacterial function but also supplied carboxyl groups for saltbridge formation. The carboxyl groups helped the polymer to firmly attach to the glass fillers. The results also imply that the CAP did not leach out of the cement; otherwise both CS and antibacterial activity would show a decreasing trend.

As stated in Introduction, lactobacillus is another main oral cavity-producing bacterium although it is not as popular as S. mutans. S. aureus and S. epidermidis are two major bacteria that often cause skin and other implant infections. To examine the antibacterial activity of CAP on these bacteria, we compared the viability of all the four bacteria after incubating with the cements. The result in Figure 5 shows that no statistically noticeable differences in viability were found among the four bacteria, even though the absolute values were different from one another. Increasing the CAP content significantly decreased the viability of all the bacteria, indicating that CAP can also kill other bacteria.

Figure 6 shows the effect of human saliva on the $S$. mutans viability after culturing with the CAP cements. No statistically significant differences in the S. mutans viability were found between the cements with and without human saliva treatment. It has been noticed that saliva can significantly reduce the antibacterial activity of the QAS or PQAS-containing materials based on the mechanism of contact inhibition $[25,26]$. The reduction was attributed to the interaction between positive charges 
on QAS or PQAS and amphiphilic protein macromolecules in saliva, thus leading to formation of a protein coating which covers the antibacterial sites on QAS or PQAS $[25,26]$. Unlike QAS or PQASA, CAP does not carry any charges. That may be why the CAP-modified cements did not show any reduction in antibacterial activity after treating with saliva.

Finally we compared YS, M, CS, DTS, FS and the $S$. mutans viability of the cements having $0 \%, 5 \%$ and $7 \%$ CAP and Fuji II LC. As shown in Table 2, the CAPmodified cements were $16 \%-17 \%$ in YS, $3.6 \%-11 \%$ in modulus, $31 \%-41 \%$ in CS, $13 \%-20 \%$ in DTS and $29 \%$ - $32 \%$ in FS lower than the cement without CAP addition. On the other hand, the CAP-modified cements were much higher (19\% and 28\% higher) in antibacterial activity than the cement without CAP addition. As compared to commercial GIC Fuji II LC, the cement with 5\% CAP showed the similar YS, M and CS, higher DTS (22\% higher) and FS (17\% higher), and lower S. mutans viability $(20 \%$ lower) values.

\section{CONCLUSION}

We have developed a novel antibacterial glass-ionomer cement. All the modified cements showed a significant antibacterial activity, accompanying with an initial CS reduction. The effect of the synthesized antibacterial polymer loading was significant. Increasing loading significantly enhanced antibacterial activity but reduced the initial CS of the formed cements. The CAP cement showed better CS values than the BAP cement, with no significant difference in antibacterial activity. The antibacterial cements showed a similar antibacterial activity to $S$. mutans, lactobacillus, $S$. aureus and $S$. epidermidis. The human saliva did not affect the antibacterial activity of the cement. The 30-day aging study indicates that the antibacterial cement may have a long-lasting antibacterial function. Future work will include optimizing the formulations and evaluating all major mechanical properties such as hardness, wear-resistance, fracture toughness and bonding to enamel and dentin, physical properties such as working and setting times, conversion, shrinkage, component leaching, water-sorption and solubility, biological properties such as cytotoxicity to pulp and gingival cells, clinically-relevant properties such as colorization, thermal expansion and fluoride release, and antibacterial test against Gram-negative bacteria.

\section{ACKNOWLEDGEMENTS}

This work was partially sponsored by NIH grant DE020614.

\section{REFERENCES}

[1] Mjor, I.A., Dahl, J.E. and Moorhead, J.E. (2002) Place- ment and replacement of restorations in primary teeth. Acta Odontologica Scandinavica, 60, 25-28. http://dx.doi.org/10.1080/000163502753471961

[2] Forss, H. and Widstrom, E. (2004) Reasons for restorative therapy and longevity of restorations in adults. Acta Odontologica Scandinavica, 62, 82-86. http://dx.doi.org/10.1080/00016350310008733

[3] Manhart, J., Garcia-Godoy, F. and Hickel, R. (2002) Direct posterior restorations: Clinical results and new developments. Dental Clinics of North America, 46, 303339. http://dx.doi.org/10.1016/S0011-8532(01)00010-6

[4] Deligeorgi, V., Mjor, I.A. and Wilson, N.H. (2001) An overview of reasons for the placement and replacement of restorations. Primary Dental Care, 8, 5-11. http://dx.doi.org/10.1308/135576101771799335

[5] Craig, R.G. and Power, J.M. (2002) Restorative dental materials. 11th Edition, Mosby-Year Book, Inc., St Louis, 614-618

[6] Wiegand, A., Buchalla, W. and Attin, T. (2007) Review on fluoride-releasing restorative materials-Fluoride release and uptake characteristics, antibacterial activity and influence on caries formation. Dental Materials, 23, 343362. http://dx.doi.org/10.1016/j.dental.2006.01.022

[7] Osinaga, P.W., Grande, R.H., Ballester, R.Y., Simionato, M.R., Delgado Rodrigues, C.R. and Muench, A. (2003) Zinc sulfate addition to glass-ionomer-based cements: Influence on physical and antibacterial properties, zinc and fluoride release. Dental Materials, 19, 212-217. http://dx.doi.org/10.1016/S0109-5641(02)00032-5

[8] Takahashi, Y., Imazato, S., Kaneshiro, A.V., Ebisu, S., Frencken, J.E. and Tay, F.R. (2006) Antibacterial effects and physical properties of glass-ionomer cements containing chlorhexidine for the ART approach. Dental Materials, 22, 467-452. http://dx.doi.org/10.1016/j.dental.2005.08.003

[9] Yamamoto, K., Ohashi, S., Aono, M., Kokubo, T., Yamada, I. and Yamauchi, J. (1996) Antibacterial activity of silver ions implanted in $\mathrm{SiO}_{2}$ filler on oral streptococci. Dental Materials, 12, 227-229.

http://dx.doi.org/10.1016/S0109-5641(96)80027-3

[10] Syafiuddin, T., Hisamitsu, H., Toko, T., Igarashi, T., Goto, N., Fujishima, A. and Miyazaki, T. (1997) In vitro inhibition of caries around a resin composite restoration containing antibacterial filler. Biomaterials, 18, 10511057. http://dx.doi.org/10.1016/S0142-9612(97)88072-6

[11] Gottenbos, B., van der Mei, H.C., Klatter, F., Nieuwenhuis, P. and Busscher, H.J. (2002) In vitro and in vivo antimicrobial activity of covalently coupled quaternary ammonium silane coatings on silicone rubber. Biomaterials, 23, 1417-1423. http://dx.doi.org/10.1016/S0142-9612(01)00263-0

[12] Thebault, P., Taffin de Givenchy, E., Levy, R., Vandenberghe, Y., Guittard, F. and Geribaldi, S. (2009) Preparation and antimicrobial behaviour of quaternary ammonium thiol derivatives able to be grafted on metal surfaces. European Journal of Medicinal Chemistry, 44, 717-724. http://dx.doi.org/10.1016/j.ejmech.2008.05.007

[13] Imazato, S., Russell, R.R. and McCabe, J.F. (1995) Antibacterial activity of MDPB polymer incorporated in den- 
tal resin. Journal of Dentistry, 23, 177-181. http://dx.doi.org/10.1016/0300-5712(95)93576-N

[14] Murata, H. (2007) Permanent, non-leaching antibacterial surfaces-2: How high density cationic surfaces kill bacterial cells. Biomaterials, 28, 4870-4879. http://dx.doi.org/10.1016/j.biomaterials.2007.06.012

[15] Lu, G.Q., Wu, D.C. and Fu, R.W. (2007) Studies on the synthesis and antibacterial activities of polymeric quarternary ammonium salts from dimethylaminoethyl methacrylate. Reactive \& Functional Polymers, 67, 355-366. http://dx.doi.org/10.1016/j.reactfunctpolym.2007.01.008

[16] Lee, S.B., Koepsel, R.R., Morley, S.W., Matyjaszewski, K., Sun, Y. and Russell, A.J. (2004) Permanent, nonleaching antibacterial surfaces. 1 . Synthesis by atom transfer radical polymerization. Biomacromolecules, 5, 877-882. http://dx.doi.org/10.1021/bm034352k

[17] Li, F., Chai, Z.G., Sun, M.N., Wang, F., Ma, S., Zhang, L., Fang, M. and Chen, J.H. (2009) Anti-biofilm effect of dental adhesive with cationic monomer. Journal of Dental Research, 88, 372-376. http://dx.doi.org/10.1177/0022034509334499

[18] Li, F., Chen, J., Chai, Z., Zhang, L., Xiao, Y., Fang, M. and Ma, S. (2009) Effects of a dental adhesive incorporating antibacterial monomer on the growth, adherence and membrane integrity of Streptococcus mutans. Journal of Dentistry, 37, 289-296.

http://dx.doi.org/10.1016/j.jdent.2008.12.004

[19] Beyth, N., Yudovin-Farber, I., Bahir, R., Domb, A.J. and Weiss, E.I. (2006) Antibacterial activity of dental composites containing quaternary ammonium polyethyleneimine nanoparticles against Streptococcus mutans. Biomaterials, 27, 3995-4002. http://dx.doi.org/10.1016/j.biomaterials.2006.03.003

[20] Chai, Z., Li, F., Fang, M., Wang, Y., Ma, S., Xiao, Y., Huang, L. and Chen, J. (2011) The bonding property and cytotoxicity of a dental adhesive incorporating a new antibacterial monomer. Journal of Oral Rehabilitation, 38, 849-856. http://dx.doi.org/10.1111/j.1365-2842.2011.02212.x

[21] Ma, S., Izutani, N., Imazato, S., Chen, J.H., Kiba, W., Yoshikawa, R., Takeda, K., Kitagawa, H. and Ebisu, S. (2012) Assessment of bactericidal effects of quaternary ammonium-based antibacterial monomers in combination with colloidal platinum nanoparticles. Dental Materials Journal, 31, 150-156.

http://dx.doi.org/10.4012/dmj.2011-180

[22] Cheng, L., Weir, M.D., Xu, H.H., Antonucci, J.M., Kraigsley, A.M., Lin, N.J., Lin-Gibson, S. and Zhou, X. (2012) Antibacterial amorphous calcium phosphate nanocomposites with a quaternary ammonium dimethacrylate and silver nanoparticles. Dental Materials, 28, 561-572. http://dx.doi.org/10.1016/j.dental.2012.01.005

[23] Cheng, L., Weir, M.D., Zhang, K., Xu, S.M., Chen, Q., Zhou, X. and Xu, H.H. (2012) Antibacterial nanocomposite with calcium phosphate and quaternary ammonium. Journal of Dental Research, 91, 460-466. http://dx.doi.org/10.1177/0022034512440579

[24] Xie, D., Weng, Y., Guo, X., Zhao, J., Gregory, R.L. and Zheng, C. (2011) Preparation and evaluation of a novel glass-ionomer cement with antibacterial functions. Dental Materials, 27, 487-496.

http://dx.doi.org/10.1016/i.dental.2011.02.006

[25] Imazato, S., Ebi, N., Takahashi, Y., Kaneko, T., Ebisu, S. and Russell, R.R.B. (2003) Antibacterial activity of bactericide-immobilized filler for resin-based restoratives. Biomaterials, 24, 3605-3609. http://dx.doi.org/10.1016/S0142-9612(03)00217-5

[26] Ebi, N., Imazato, S., Noiri, Y. and Ebisu, S. (2001) Inhibitory effects of resin composite containing bactericideimmobilized filler on plaque accumulation. Dental $\mathrm{Ma}$ terials, 17, 485-491. http://dx.doi.org/10.1016/S0109-5641(01)00006-9

[27] Jung, J.H., Pummangura, S., Chaichantipyuth, C., Patarapanich, C., Fanwick, P.E., Chang, C.J. and Mclaughlin, J.L. (1990) New bioactive heptenes from melodorum fruitcosum (annonaceae). Tetrahedron, 46, 5043-5054. http://dx.doi.org/10.1016/S0040-4020(01)87811-X

[28] Jones, J.B. and Young, J.M. (1968) Carcinogenicity of lactones III: The reactions of unsaturated 4-lactones with 1-cysteine. Journal of Medicinal Chemistry, 11, 1176. http://dx.doi.org/10.1021/jm00312a017

[29] Lattmann, E., Dunn, S., Niamsanit, S. and Sattayasai, N. (2005) Synthesis and antibacterial activities of 5-hydroxy4-amino-2(5H)-furanones. Bioorganic \& Medicinal Chemistry Letters, 15, 919-921. http://dx.doi.org/10.1016/j.bmcl.2004.12.051

[30] Lattmann, E., Coombs, J. and Hoffmann, H.M.R. (1996) Paranofuranones via lewis acid mediated hetero-dielsalder reactions of 4-Furan-2(5H)-ones. A convergent route to the manoalide substructure. Synthesis, 171-177. http://dx.doi.org/10.1055/s-1996-4158

[31] Martinelli, D., Grossmann, G., Sequin, U., Brandl, H. and Bachofen, R. (2004) Effects of natural and chemically synthesized furanones on quorum sensing in Chromobacterium violaceum. BMC Microbiology, 4, 25. http://dx.doi.org/10.1186/1471-2180-4-25

[32] Xie, D., Weng, Y. and Zhao, J. (2009) Alternative methacrylate-tethering methods for resin-modified glass-ionomer cements. Journal of Applied Polymer Science, 111, 869-875.

[33] Wu, W., Xie, D., Puckett, A. and Mays, J. (2003) Synthesis and formulation of vinyl-containing polyacids for improved light-cured glass-ionomer cements. European Polymer Journal, 39, 663-670. http://dx.doi.org/10.1016/S0014-3057(02)00301-4

[34] Xie, D., Yang, Y., Zhao, J., Park, J.G. and Zhang, J.T. (2007) A novel comonomer-free light-cured glass-ionomer system for reduced cytotoxicity and enhanced mechanical strength. Dental Materials, 23, 994-1003. http://dx.doi.org/10.1016/j.dental.2006.09.001

[35] Cattani-Lorente, M.A., Dupuis, V., Moya, F., Payan, J. and Meyer, J.-M. (1999) Comparative study of the physical properties of a polyacid-modified composite resin and a resin-modified glass ionomer cement. Dental Materials, 15, 21-32. http://dx.doi.org/10.1016/S0109-5641(99)00010-X

[36] Davidson, C.L. and Mjor, I.A. (1999) Advances in glassIonomer cements. Quintessence Publishing Co, Chicago. 


\section{LIST OF THE ABBREVIATIONS}

CS: compressive strength; M: modulus;

DTS: diametral tensile strength;

FS: flexural strength;

GIC: glass-ionomer cement;

PAA: poly(acrylic acid);
GA: glycolic acid;

DCA: 2,3-dichloromalealdehydic acid;

GM: glycidyl methacrylate;

DBA: dibromomalealdehydic acid;

CAP: chlorine-containing antibacterial polymer; BAP: bromine-containing antibacterial polymer. 